\title{
STRATEGI PENINGKATAN PENERAPAN METODE PEMBELAJARAN E-LEARNING PADA PROGRAM STUDI PGSD FKIP UST
}

\author{
C. Indah Nartani, Kristi Wardani, dan Biya Ebi Praheto \\ Program Studi Pendidikan Guru Sekolah Dasar \\ Universitas Sarjanawiyata Tamansiswa Yogyakarta \\ biya.ebi@ustjogja.ac.id
}

\begin{abstract}
The purpose of this research is to analyze the students' perception about the application of e-learning learning in Primary School Teacher Education Study Program (PGSD), Faculty of Teacher Training and Education (FKIP), Sarjanawiyata Tamansiswa University (UST). The type of research in this study is survey research. Survey research is a study by using questionnaires as an instrument of data collection. While the method used is descriptive analytical. The place of this research is conducted in the Study Program PGSD UST which is located at Campus FKIP UST Jalan Batikan Tuntungan UH 3/1043 Yogyakarta. Technique of collecting data in this research is done on primary data and secondary data. Data analysis technique used is descriptive analysis. The results showed that the perception of students and lecturers into the high category of application of e-learning based learning in PGSD FKIP UST. It can be seen the average value of the respondents both students and lecturers reached 80.6 are in the high category. In addition, 118 student respondents from 156 respondents obtained the value of a 5-scale questionnaire in the high category or by $78 \%$ of respondents are in the high category. Then, 22 respondents of lecturers from 27 respondents obtained the value of questionnaire scale 5 which is in the high category or $81.48 \%$ of respondents are in the high category. It shows the positive response of students to the application of e-learning learning in PGSD study program. Thus e-learning based learning can be applied well to the PGSD study because of the high students and lecturers.
\end{abstract}

Keywords: student perception, e-learning, Primary School Teacher Education Study Program (PGSD)

Abstrak. Tujuan dari penelitian ini adalah untuk menganalisis persepsi mahasiswa tentang penerapan pembelajaran e-learning pada Program Studi Pendidikan Guru Sekolah Dasar, Fakultas Keguruan dan Ilmu Pendidikan, Universitas Sarjanawiyata Tamansiswa. Jenis penelitian dalam penelitian ini yaitu penelitian survey. Penelitian survey adalah penelitian dengan menggunakan kuesioner sebagai instrumen pengumpulan datanya. Sedangkan metode yang digunakan yaitu deskriptif analitis. Adapun tempat penelitian ini dilakukan di Prodi PGSD UST yang beralamat di Kampus FKIP UST Jalan Batikan Tuntungan UH 3/1043 Yogyakarta. Teknik pengumpulan data dalam penelitian ini dilakukan atas data primer dan data sekunder. Teknik analisis data yang digunakan adalah analisis deskriptif. Hasil penelitian menunjukkan bahwa persepsi mahasiswa dan dosen masuk ke dalam kategori tinggi terhadap penerapan pembelajaran berbasis e-learning di prodi PGSD FKIP UST. Dapat diketahui nilai rata-rata dari responden baik mahasiswa maupun dosen mencapai 80,6 berada pada kategori tinggi. Selain itu, 118 responden mahasiswa dari 156 responden memperoleh nilai angket skala 5 yang berada pada kategori tinggi atau sebesar $78 \%$ responden 
berada pada kategori tinggi. Kemudian, 22 responden dosen dari 27 responden memperoleh nilai angket skala 5 yang berada pada kategori tinggi atau sebesar $81,48 \%$ responden berada pada kategori tinggi. Hal tersebut menunjukkan adanya respon positif mahasiswa terhadap penerapan pembelajaran e-learning di prodi PGSD. Dengan demikian pembelajaran berbasis e-learning dapat diterapkan dengan baik pada prodi PGSD karena keberteriaman mahasiswa dan dosen tinggi.

Kata kunci: persepsi mahasiswa, pembelajaran e-learning, Program Studi PGSD

\section{Pendahuluan}

Pendidikan harus selalu berkembang mengikuti kondisi saat ini, sehingga pendidikan dapat memberikan manfaat yang berarti bagi peserta didik guna mencapai tujuan pendidikan Nasional. Salah satunya pendidikan tinggi. Pendidikan tinggi harus relevan dengan dunia kerja dan kebutuhan masyarakat, sehingga menghasilkan lulusan yang berkualitas. Untuk mewujudkannya, pada Pendidikan Tinggi mulai merevitalisasi komponen-komponen dalam pembelajaran diantaranya kurikulum dan metode pembelajaran sehingga dapat menghasilkan mutu bagi dunia pendidikan tinggi di Indonesia agar menghasilkan sumber daya manusia berkualitas dan bersaing di tingkat global terkait dengan sistem pendidikan nasional. Salah satunya yaitu pemanfaatan internet dalam proses pembelajaran. Penggunaan internet dalam proses pembelajaran dikenal dengan istilah e-learning. E-learning membuat pembelajaran dapat lebih terbuka dan fleksibel. Pembelajaran dapat terjadi kapan saja, dimana saja, dan dengan siapa saja (Rahmaniah, dkk, 2012). Oleh sebab itu, E-learning dapat dikatakan telah menjadi salah satu cara utama untuk memberikan pendidikan di seluruh dunia (Omer, et al. 2015: 267). Selain itu, e-learning juga dapat berarti belajar melalui media elektronik, seperti radio, televisi, video, CD-ROM, jaringan komputer. Sekarang, e-learning berarti belajar dan mengajar melalui jaringan internet. Pelajar dan guru dapat belajar dengan menggunakan sumber daya dalam sistem internet untuk belajar dan mengajar secara efektif(Kaewkiriya, 2013: 62). Warsita (2011: 136) juga menyebutkan bahwa perkembangan teknologi internet memberikan nuansa baru sistem pembelajaran jarak jauh yang lebih terbuka lagi. Sistem pembelajaran berbasis web yang popular dengan sebutan elektronik learning (e-learning), web-besed training atau kadang disebut webbased education dan lain-lain. Selain itu, E-learning mengacu pada penggunaan teknologi informasi dan komunikasi untuk mengaktifkan akses ke sumber belajar/ mengajar online (Arkorful \& Abaidoo, 2014: 2).

Hal tersebut juga terjadi di Program Studi PGSD FKIP UST. Program Studi PGSD Fakultas Keguruan dan Ilmu Pendidikan Universitas Sarjanawiyata Tamansiswa Yogyakarta merupakan salah satu lembaga pendidikan tinggi di bawah Kemenristek Dikti mendapat Hibah penyusunan bahan ajar e-learning pada mata kuliah "Pengembangan Media Pembelajaran" tahun 2016. Berangkat dari rintisan tersebut, prodi PGSD FKIP UST mengembangkan bahan ajar untuk mata kuliah berbasis e-learning. Mata kuliah media pembelajaran merupakan salah satu mata kuliah wajib pada program studi PGSD. Mata kuliah ini menekankan pada pemahaman konsep, penalaran, pengambilan keputusan yang berkaitan dengan proses pengembangan indikator dan materi pembelajaran. Pada tahun ajaran 2016/2017 dikembangkan model pembelajaran e-learning pada matakuliah media pembelajaran.

Hibah penyusunan bahan ajar e-learning pada mata kuliah "Pengembangan Media Pembelajaran" tahun 2016 yang diperoleh Prodi PGSD serta berbagai permasalahan dalam mata kuliah media pembelajaran menjadi cikal bakal dikembangkannya materi sertametodepembelajaranberbasise-learning. 
Dari sekian mata kuliah yang terdapat di Prodi PGSD baru mata kuliah media pembelajaran yang telah mengembangkan dan menerapkan materi serta metode pembelajaran berbasis e-learning. Sejauh ini baru mata kuliah media pembelajaran yang menerapkan pembelajaran berbasis e-learning, sedangkan mata kuliah lainnya belum. Oleh sebab itu, diperlukan sebuah penelitian mendalam terkait penerapan e-learning yang sudah berjalan guna menyusun strategi penerapan e-learning untuk mata kuliah lain di Prodi PGSD. E-learning dapat memuat multimedia pendidikan. Multimedia tersebut dapat membantu dosen maupun mahasiswa untuk belajar dikarenakan menggabungkan berbagai unsur di dalamnya seperti teks, video, gambar, suara, animasi, dan lain sebagainya ((Praheto, Andayani, Rohmadi, \& Wardani, 2017). Beberapa penelitian berkaitan dengan pembelajaran e-learning sudah banyak dilakukan sebelumnya. Penelitian yang dilakukan Damayanti, dkk. (2007) berjudul E-learning pada Pendidikan Jarak Jauh: Konsepyang Mengubah MetodePembelajaran di Perguruan Tinggi di Indonesia. Dalam penelitiannya Damayanti, dkk. menyebutkan bahwa pengembangan e-learning merupakan suatu upaya untuk meningkatkan kemudahan pada proses belajar mahasiswa. Selain itu, penelitian yang dilakukan oleh Sutomo (2012) dengan judul E-learning sebagai Alternatif Model Pembelajaran dalam Upaya Meningkatkan Mutu di Perguruan Tinggi menyebutkan bahwa e-learning membawa pengaruh terjadinya proses transformasi pendidikan konvensional ke pendidikan modern dalam bentuk digital, baik secara isi (content) dan sistemnya. Kemudian, penelitian yang dilakukan Suteja, dkk. (2010) dengan judul Personalization Sistem E-Learning Berbasis Ontology. Suteja, dkk. mengemukakan bahwa sistem e-Learning yang dikembangkan memanfaatkan ontology sebagai proses memetakan pengetahuan pembelajar dalam proses belajar dan melatih konsep pemahaman terhadap materi. Dalam proses tersebut dapat diperoleh model perkembangan pembelajar yang lebih baik dan dapat mengadaptasikan isi dan struktur materi dari pembelajar yang berhasil dalam belajar online ke pembelajar lain yang baru ikut serta dalam sistem ini. Melihat penelitian terdahulu belum ada penelitian berkaitan dengan pembelajaran e-learning di prodi PGSD. Oleh sebab itu dalam penelitian ini akan melakukan studi awal guna menerapkan pembelajaran e-learning di prodi PGSD.

Berdasarkan hal tersebut dibutuhkan persepsi atau tanggapan mahasiswa maupun dosen terhadap penerapan pembelajaran e-learning guna menyusun strategi mengembangkanmateriataupunpembelajaran e-learning untuk mata kuliah lainnya. Hal tersebut dikarenakan, Pembelajaran melalui e-learning memerlukan desain yang jelas, diantaranya terkait dengan komponen e-learning (Saiffudin, 2017: 4) Oleh sebab itu, tujuan penelitian ini adalah mengkaji tentang persepsi mahasiswa dan dosen terhadap penerapan metode pembelajaran berbasis edan strategi apa yang harus diterapkan pada Prodi PGSD FKIP UST dalam meningkatkan penerapan metode pembelajaran e-learning.

\section{Metode}

Jenis penelitian dalam penelitian ini yaitu penelitian survey. Penelitian survey adalah penelitian dengan menggunakan kuesioner sebagai instrumen pengumpulan datanya. Sedangkan metode yang digunakan yaitu deskriptif analitis. Data dan informasi dikumpulkan dari responden dengan menggunakan kuesioner. Setelah data diperoleh, hasilnya dipaparkan secara deskriptif. Pada akhir penelitian analisis gambaran tentang fakta-fakta, sifat dan hubungan antar gejala dengan penjelasan (explanatory).

Penelitian ini dilakukan di Prodi PGSD UST yang beralamat di Kampus FKIP UST Jalan Batikan Tuntungan UH 3/1043 Yogyakarta. Populasi dalam penelitian yang digunakan adalah mahasiswa PGSD UST semester 5 yang mengikuti mata kuliah Media Pembelajaran yang berjumlah 379 
orang. Besarnya sampel penelitian ini adalah 156 mahasiswa yang diambil secara cluster random sampling (sampling acak berdasarkan kelas). Kelas yang dijadikan sample responden adalah kelas 5E,5F, 4G dan $4 \mathrm{H}$. Kemudian untuk dosen terdiri dari 27 responden.

Teknik pengumpulan data dalam penelitian ini dilakukan atas data primer dan data sekunder. (1) Data primer. Teknik pengumpulan data primer menggunakan kuesioner dan wawancara. (2) Data sekunder. Data sekunder adalah informasi yang tidak secara langsung diperoleh dari responden. Analisis data dilakukan terhadap kuesioner yang telah dibagikan. Teknik analisis data yang digunakan adalah analisis deskriptif.

\section{Hasil dan Pembahasan}

\section{Persepsi Mahasiswa dan Dosen terhadap Pembelajaran E-Learning di PGSD}

Persepsi mahasiswa dan dosen terkait dengan penerapan pembelajaran e-learning di program studi PGSD diperoleh dari data persebaran angket. angket dibagikan kepada 4 kelas sampel mahasiswa semester 5 yaitu kelas 5E, 5F, 5G, dan 5H. Angket berkaitan dengan pengetahuan, motivasi, kemudahan penggunaan, manfaat, efisiensi, daya tarik, dan nilai keharusan terhadap penerapan pembelajaran e-learning.secara terperinci persepsi mahasiswa terhadap penerapan pembelajaran e-learning dibahas sebagai berikut.

Tabel 1. Persepsi Mahasiswa berdasarkan Angket

\begin{tabular}{|c|c|c|c|}
\hline \multirow{2}{*}{ No. } & \multirow{2}{*}{ Aspek } & \multicolumn{2}{|c|}{ Nilai } \\
\hline & & Mahasiswa & Dosen \\
\hline 1 & Pengetahuan & 3,41 & 4,00 \\
\hline 2 & Motivasi & 3,47 & 3,28 \\
\hline 3 & Kemudahan Penggunaan & 3,3 & 3,83 \\
\hline 4 & Manfaat & 3,42 & 3,38 \\
\hline 5 & Efisiensi & 3,55 & 3,56 \\
\hline 6 & Daya Tarik & 4 & 4,20 \\
\hline \multirow[t]{2}{*}{7} & Suatu Keharusan & 4 & 4,30 \\
\hline & Rata-rata & 3,59 & 3,79 \\
\hline
\end{tabular}

Berdasarkan tabel 1. di atas dapat diketahui pemaparan setiap aspek dalam persepsi mahasiswa dan dosen sebagai berikut.

\section{a. Pengetahuan}

Pengetahuan berkaitan dengan ketahuan siswa terhadap pembelajaran e-learning. Dapat dilihat pada tabel 1 bahwa mahasiswa sebagian besar tahu terkait dengan pembelajaran e-learning dari total 156 responden dengan soal berskala 5 pada point pengetahuan terhadap pembelajaran e-learning memiliki nilai rata-rata 3,41. Kemudian untuk dosen dengan responden 27 dosen mencapai nilai 4,00 sehingga dapat menunjukkan bahwa secara keseluruhan dosen tahu dan paham terhadap pembelajaran e-learning. Hal tersebut menunjukkan bahwa pembelajaran e-learning sudah tidak asing lagi bagi mahasiswa terutama bagi dosen. Selain itu diimbangi dengan jaringan internet yang ada dikampus yang sudah cukup baik menjadikan pembelajaran e-learning dapat diterapkan dengan baik. Akan tetapi terkait dengan jaringan internet perlu ditingkatkan kembali dari segi kecepatan maupun jangkauan sehingga dapat memaksimalkan penerapan pembelajaran berbasis e-learning di prodi PGSD FKIP UST.

\section{b. Motivasi}

Motivasi dapat diartikan sebagai kekuatan (energi) seseorang yang dapat menimbulkan tingkat persistensi dan 
entusiasmenya dalam melaksanakan suatu kegiatan, baik yang bersumber dari dalam diri individu itu sendiri (motivasi intrinsik) maupun dari luar individu (motivasi ekstrinsik) (Sudrajat dalam Nugrahantini, 2013). Dapat dilihat pada tabel 1 bahwa responden berpersepsi baik dan memberikan kategori tinggi terhadap pembelajaran e-learning yang dapat membantu mahasiswa dalam mencapai kompetensi pembelajaran. Selain itu, dengan adanya pembelajaran e-learning dapat dilakukan mahasiswa setiap saat dan di mana saja sehingga memudahkan mahasiswa untuk belajar. Namun, di sisi lain pembelajaran e-learning juga dianggap sulit dan kompleks serta akan menambah beban tugas mahasiswa. Cukup banyak mahasiswa yang menyatakan hal tersebut dikarenakan pembelajaran e-learning membutuhkan jaringan internet serta dimungkinkan tampilan dari pembelajaran e-learning yang kompleks akan membingungkan mahasiswa dalam mengakses pembelajaran. Selain itu, mahasiswa sudah merasa terbebani dengan tugas manual klasikal yang cukup banyak sehingga dengan adanya pembelajaran e-learning dianggap akan menambah beban tugas mahasiswa. Kemudian terkait dengan persepsi dosen menunjukkan bahwa sebagian besar dosen sudah menerapkan pembelajaran berbasis e-learning, walaupun belum semua dosen menerapkan pembelajaran e-learning. Selain itu, sebagian besar dosen dengan skala 4,11 menyatakan bahwa pembelajaran e-learning menjadikan pembelajaran dapat dilakukan dosesn setiap saat, serta skala 4,22 menunjukkan bahwa penggunaan pembelajaran e-learning memudahkan dosen untuk mencapai capaian pembelajaran yang dirumuskan dalam RPS. Hal tersebut menunjukkan bahwa dengan adanya pembelajaran e-learning, pembelajaran tidak hanya terfokus pada pembelaran berbasis klasikal. Disisi lain pembelajaran e-learning bukan merupakan pembelajaran yang sulit untuk diterapkan serta tidak memberikan tambahan beban tugas bagi dosen.

\section{c. Kemudahan Penggunaan}

Kemudahan penggunaan berkaitan dengan bagaimana mahasiswa mengakses pembelajaran e-learning. Dapat diketahui pada tabel 1 bahwa mahasiswa berpersepsi akan menggunakan e-learni dengan perolehan kategori sedang menuju tinggi yaitu rata-rata 3,3 dari skor maksimal 5. Hal tersebut menunjukkan bahwa mahasiswa akan mengakses e-learni dan memanfaatkannya secara maksimal baik dalam pembelajaran di kelas maupun di luar kelas. Selain itu, pembelajaran e-learning juga akan dibuka mahasiswa setiap saat sebagai bahan pelajaran meskipun tidak ada tugas yang dibebankan menggunakan e-learning. Hal tersebut dapat disimpulkan bahwa dengan penerapan e-learning didalam pembelajaran tidak ada kendala yang cukup memberatkan bagi mahasiswa untuk mengaksesnya setiap saat. Kemudian berkaitan dengan dosen, menunjukkan bahwa pembelajaran e-learning sangat memudahkan dosen untuk menyampaikan materi dan tugas kepada mahasiswa dengan poin skala sangat tinggi yaitu 4,37. Selain itu sebagian besar dosen dengan poin skala di atas 3,5 menyatakan bahwa akan selalu mengunggah materi dan tugas serta meng-update materi dalam e-learning yang digunakan oleh dosen. Hal tersebut menunjukkan bahwa pembelajaran e-learning merupakan pembelajaran yang mudah dan dapat diterapkan oleh dosen. Pembelajaran didalam perkembangannya harus selalu mengikuti perkembangan jaman. Sebagaimana internet tidak dapat lepas dalam kehidupan manusia sehingga pembelajaran berbasis internet dapat memudahkan dosen dalam proses pembelajaran. 


\section{d. Manfaat}

Kebermanfaatan penerapan pembelajaran e-learning dalam proses belajar mengajar di prodi PGSD berkaitan dengan proses pembelajaran. Berdasarkan tabel 1 dapat diketahui penerapan pembelajaran berbasis e-learning memberikan manfaat yang tinggi dalam proses belajar mengajar. Selain menjadikan interaksi dosen dan mahasiswa bertambah juga menjadikan pembelajaran tidak monoton dan mahasiswa dapat memperoleh variasi sumber belajar yang beragam secara on line serta dosen juga dapat menggunakan sumber belajar yang bervariasi secara on line. Selain itu, penerapan e-lerning menjadikan pembelajaran lebih menarik dan tidak membosankan.

\section{e. Efisiensi}

Tampak pada tabel 1 menunjukkan persepsi mahasiswa terhadap efisiensi pembejaranan berbasis e-learning yang dapat mempercepat mahasiswa dalam mempelajari bahan materi. Sebagian besar mahasiswa menyatakan bahwa dengan adanya pembelajaran e-learning dapat membantu mahasiswa mempelajari unit materi secara ringkas, jelas, serta membutuhkan waktu yang tidak lama. Hal tersebut dapat berdampak pada penguasaan kompetensi bagi mahasiswa secara efisien. Hal tersebut berbanding lurus dengan semakin baiknya proses pembelajaran dengan penerapan pembelajaran berbasis e-learning. Kemudian dapat ditunjukkan bahwa pembejaranan berbasis e-learning yang dapat membantu dosen menyampaikan materi pembelajaran. Hampir seluruh dosen menyatakan bahwa dengan adanya pembelajaran e-learning dapat membantu dosen menyampaikan unit materi secara ringkas dan jelas, serta membutuhkan waktu yang tidak lama. Hal tersebut dapat berdampak pada penguasaan kompetensi bagi mahasiswa secara efisien. Hal tersebut berbanding lurus dengan semakin baiknya proses pembelajaran dengan penerapan pembelajaran berbasis e-learning.

\section{f. Daya Tarik}

Penerapan pembelajaran e-learning menjadikan materi disajikan secara menarik tidak hanya monoton berbasis materi berbentuk tulisan. Hal tersebut menjadikan pembelajaran e-learning menarik bagi mahasiswa. Selain itu, e-learning dapat dikatakan sebagai media. Penerapan media yang inovatif akan berbanding lurus dengan hasil belajar (Praheto, 2013). Berdasarkan tabel 1 bahwa penerapan pembelajaran e-learning memiliki daya tarik yang tinggi bagi mahasiswa. Hal tersebut dikarenakan penerapan e-learning membuat pembelajaran menjadi interaktif, meskipun pembelajaran tidak dilakukan di dalam kelas dan dapat diakses mahasiswa kapan pun. Selain itu, hal lain yang menjadikan daya tarik dalam penerapan e-learning adalah dosen dapat memasukkan berbagai jenis sumber ke dalam materi yang diunggah pada e-learning, misalnya video, gambar, materi, hingga evaluasi pembelajaran. Oleh karena itu, dapat membuat mahasiswa merasa senang dan tertarik untuk mengakses pembelajaran melalui e-learning, serta dosen juga merasa senang dengan pembelajaran e-learning karena dapat membuat pembelajaran menjadi ringkas dan menarik..

\section{g. Suatu keharusan}

Melihat peran penting pembelajaran berbasis e-learning serta manfaatnya maka pembelajaran e-learning menjadi suatu keharusan untuk diterapkan di prodi PGSD. Berdasarkan tabel 1 dapat diketahui persepsi mahasiswa maupun dosen yang menyatakan bahwa pembelajaran e-learning perlu dan harus diterapkan di program studi PGSD. Hal tersebut menjadi suatu kebutuhan untuk mengembangkan proses pembelajaran di prodi PGSD yang dapat membantu tercapainya tujuan pembelajaran dengan 
cepat dan baik, serta mengembangkan pembelajaran modern berbasis pemanfaatan internet.

Secara keseluruhan penghitungan hasil angket yang berjumlah 23 soal dan nilai setiap soal menggunakan skala 5 (1-5) dari 156 responden yang berasal dari kelas 4E, 4F, 4G, dan $4 \mathrm{H}$ untuk mahasiswa dan 27 responden untuk dosen sebagai berikut.

Tabel 2. Kurva normal skala lima

\begin{tabular}{cccc}
\hline $\begin{array}{c}\text { Interval } \\
\text { Mahasiswa }\end{array}$ & $\begin{array}{c}\text { Kategori } \\
\text { Dosen }\end{array}$ & Frekuensi \\
\hline $91,95<\mathrm{x}$ & Sangat Tinggi & 5 & 3 \\
$76,65<\mathrm{x} \leq 91,95$ & Tinggi & 118 & 22 \\
$61,35<\mathrm{x} \leq 76,65$ & Sedang & 32 & 2 \\
$46,05<\mathrm{x} \leq 61,35$ & Rendah & 1 & 0 \\
$\mathrm{x}<46,05$ & Sangat Rendah & 0 & 0 \\
\hline Rata-rata skor adalah 80,6 berada pada kategori tinggi.
\end{tabular}

\section{Diagram}

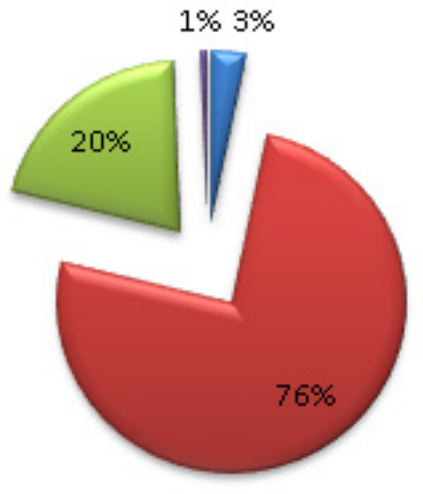

QSangat Tinggi

- T inggi

$\square$ Sedang

BRendah

$\square$ Sangat Rendah

Gambar 1. Diagram Persepsi Mahasiswa

\section{Diagram}

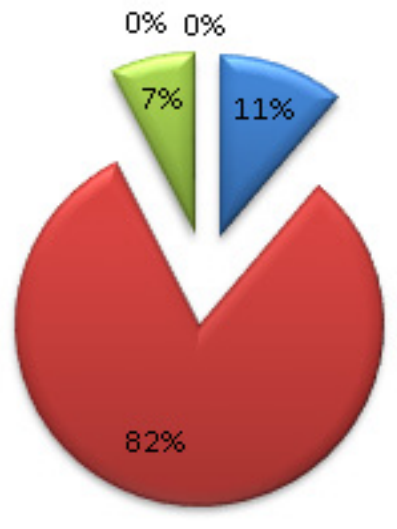

Sangat Ting gi

- T inggi

$\square$ Sedang

arendah

Q Sangat Rendah

Gambar 2. Diagram Persepsi Dosen 
Berdasarkan tabel 2 dan diagram di atas dapat diketahui bahwa persepsi mahasiswa dan dosen masuk ke dalam kategori tinggi terhadap penerapan pembelajaran berbasis e-learning di prodi PGSD FKIP UST. Dapat diketahui nilai rata-rata dari responden baik mahasiswa maupun dosen mencapai 80,6 berada pada kategori tinggi. Selain itu, 118 responden mahasiswa dari 156 responden memperoleh nilai angket skala 5 yang berada pada kategori tinggi atau sebesar $78 \%$ responden berada pada kategori tinggi. Kemudian, 22 responden dosen dari 27 responden memperoleh nilai angket skala 5 yang berada pada kategori tinggi atau sebesar 81,48\% responden berada pada kategori tinggi. Hal tersebut menunjukkan adanya respon positif mahasiswa terhadap penerapan pembelajaran e-learning di prodi PGSD. Dengan demikian pembelajaran berbasis e-learning dapat diterapkan dengan baik pada prodi PGSD karena keberteriaman mahasiswa dan dosen tinggi.

\section{Strategi Penerapan Pembelajaran E-Learning di PGSD}

Berdasarkan data dan pembahasan hasil data dapat dirumuskan beberapa strategi terkait pengembangan penerapan pembelajaran e-lerning di Prodi PGSD FKIP UST. Strategi tersebut berkaitan dengan Program studi, dosen, mahasiswa dan fasilitas. Berikut strategi yang dapat diterapkan dalam pengembangan pembelajaran e-learning. Pertama, strategi bagi program studi, yaitu: a) Program studi menyusun kebijakan terkait dengan penerapan pembelajaran e-learning bagi seluruh dosen PGSD, b) Program studi memberikan fasilitas pengembangan kemampuan penerapan pembelajaran e-learning bagi dosen PGSD, c) Program studi mensosialisasikan penerapan pembelajaran e-learning bagi mahasiswa dan dosen PGSD. Kedua, strategi bagi Dosen, yaitu a) Dosen mengembangkan potensi penerapan pembelajaran e-learning melalui berbagai kegiatan seperti pelatihan dan seminar, b) Setiap dosen harus memiliki blog, web, atau program lain guna penerapan pembelajaran e-learning, c) Dosen membuat materi yang menyenangkan dan bervariasi dalam pembelajaran e-learning serta selalu mengupdate materi dalam e-learning yang digunakan, d) Dosen selalu mengajak mahasiswa untuk memanfaatkan dan mengkases pembelajaran e-learning. Ketiga, strategi bagi mahasiswa, yaitu: a) Mahasiswa memanfaatkan dan mengakses pembelajaran e-learning secara konsisten, b) Mahasiswa memperoleh tutorial dengan dosen dalam mengakses pembelajaran e-learning Keempat, Strategi terhadap Fasilitas, yaitu: a) Peningkatan jaringan internet di kampus, b) Memperbanyak akses stop kontak listrik yang memadai bagi mahasiswa di luar kelas, c) Memberikan tempat nyaman bagi mahasiswa untuk mengakses internet di luar kelas.

\section{Simpulan}

Pembelajaran harus selalu berkembang sesuai dengan kemajuan jaman sehingga penerapan internet dalam pembelajaran merupakan suatu keharusan. Hal tersebut dapat menjadikan pembelajaran berbasis e-learning sangat membantu tercapainya tujuan pembelajaran. Berdasarkan hasil penelitian menunjukkan bahwa persepsi mahasiswa dan dosen masuk ke dalam kategori tinggi terhadap penerapan pembelajaran berbasis e-learning di prodi PGSD FKIP UST. Dapat diketahui nilai ratarata dari responden baik mahasiswa maupun dosen mencapai 80,6 berada pada kategori tinggi. Selain itu, 118 responden mahasiswa dari 156 responden memperoleh nilai angket skala 5 yang berada pada kategori tinggi atau sebesar $78 \%$ responden berada pada kategori tinggi. Kemudian, 22 responden dosen dari 27 responden memperoleh nilai angket skala 5 yang berada pada kategori tinggi atau sebesar $81,48 \%$ responden berada pada kategori tinggi. Hal tersebut menunjukkan adanya respon positif mahasiswa terhadap penerapan pembelajaran e-learning di prodi 
PGSD. Dengan demikian pembelajaran baik pada prodi PGSD karena keberteriaman berbasis e-learning dapat diterapkan dengan mahasiswa dan dosen tinggi.

\section{Daftar Pustaka}

Arkorful, Valentina and Abaidoo Nelly. (2014). The role of e-learning, the advantages and disadvantages of its adoption in Higher Education. International Journal of Education and Research. Vol. 2 No. 12 pp. 397-410.

Darmayanti, Tri, dkk. (2007). E-learning pada Pendidikan Jarak Jauh: Konsep yang Mengubah Metode Pembelajaran di Perguruan Tinggi di Indonesia. Jurnal Pendidikan Terbuka dan Jarak Jauh, Volume 8, Nomor 2, September 2007, 99-113

Kaewkiriya, Thongchai. (2013). A Design and Development of E-learning Content For Multimedia Technology Using Multimedia Game. International Journal of Software Engineering \& Applications (IJSEA), Vol.4, No.6, pp. 61-69.

Nugrahantini, Nanik Istantri. (2013). Motivasi Kerja Guru Di SMP Negeri Sub Rayon 2 Muntilan Kabupaten Magelang. Jurnal Varia Pendidikan, Vol. 25, No. 1, Hlm. 24-33.

Omer, Mohammed, et.al. (2015). E-learning Opens Door to the Global Community: Novice Users' Experiences of E-learning in a Somali University. MERLOT Journal of Online Learning and Teaching. Vol. 11, No. 2, pp. 267-279.

Praheto, Biya Ebi. (2013). Penerapan Quantum Learning dengan Media Permainan Puzzle untuk Meningkatkan Kemampuan Membaca Aksara Jawa pada siswa kelas 3B SD Negeri 1 Wangon Kab. Banyumas. Tesis. Pascasarjana Pendidikan Bahasa Jawa UNS.

Praheto, B. E., Andayani, Rohmadi, M., \& Wardani, N. E. (2017). Peran Multimedia Interaktif Dalam Pembelajaran Keterampilan Berbahasa Indonesia Di Pgsd. Proceedings, 173177. Retrieved from http://jurnal.unissula.ac.id/index.php/ELIC/article/view/1224

Rahmaniah, Anna, dkk. (2012). Pengembangan Bahan Ajar Berbasis E-Learning Pada Materi Hidrokarbon dan Minyak Bumi Kelas X Semester 2. Jurnal Penelitian, (Online). Jurnal online.um.ac.id/artikel/Anna Rahmaniah.pdf)

Saiffudin, Much. Fuad. (2017). E-learning dalam Persepsi Mahasiswa. Jurnal Varia Pendidikan. Vol. 29, No. 2, Hlm. 102-109.

Suteja, Bernad Renaldy, dkk. (2010). Personalization Sistem E-0learning Berbasis Ontology. Jurnal Makara Sains, Vol. 14, No. 2, 192-200

Sutomo, Moh. (2012). E-learning sebagai Alternatif Model Pembelajaran dalam Upaya Meningkatkan Mutu di perguruan Tinggi. Jurnal Falasifa vol. 3 no 1. Maret 2012 149159

Warsita, Bambang. (2011). Pendidikan Jarak Jauh : Perancangan, Pengembangan, Implementasi, dan Evaluasi Diklat. Bandung : PT Remaja Rosdakarya 